
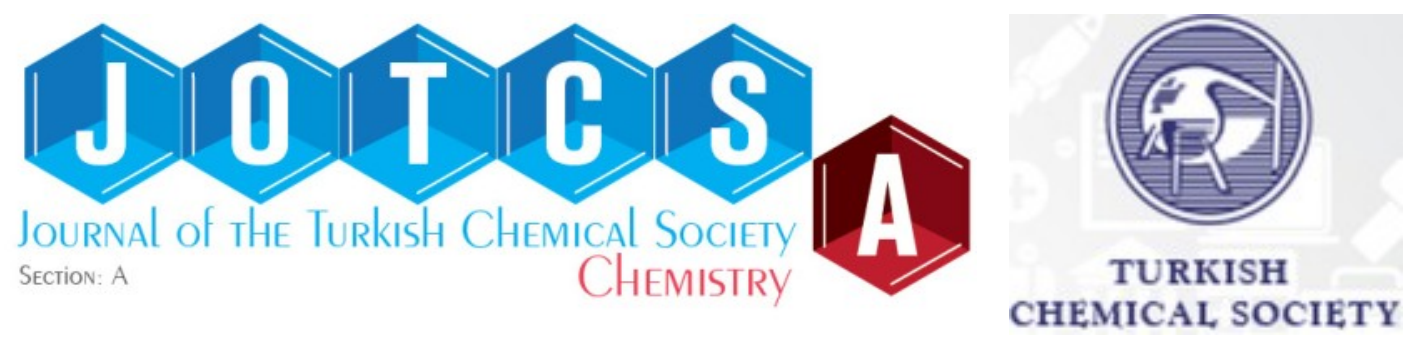

\title{
Comparative Determination of Melittin by Capillary Electrophoretic Methods
}

\author{
Melda Akay (D), Zeynep Kalaycıoğlu ${ }^{1}$, Sevgi Kolayı² iD, F. Bedia Erim¹ \\ ${ }^{1}$ Istanbul Technical University, Department of Chemistry, Istanbul, Turkey \\ ${ }^{2}$ Karadeniz Technical University, Department of Chemistry, Trabzon, Turkey
}

\begin{abstract}
Bee venom from honey bees (Apis Mellifera L.) is known to have many pharmacological and biological properties. Melittin, a peptide consisting of 26 amino acids, is known as the main component of bee venom. The study aims to develop a rapid capillary electrophoresis method for separating and quantifying melittin in honeybee venom. Since melittin is a basic peptide, it will adhere to the capillary wall during separation. Two different methods were developed in this study for the capillary electrophoretic separation of melittin. As a first approach, a low $\mathrm{pH}$ buffer system was used. For the second approach, the capillary column was coated with a positively charged polymer (PEI). With both methods developed, the migration of melittin in the capillary was achieved by preventing wall adsorption. Melittin migrated in 6 min when the low-pH buffer system was applied, whereas its migration time is longer than 10 min in the PEIcoated capillary column. Thus, a low-pH buffer system was preferred for the analysis of the actual beevenom sample. $100 \mathrm{mmol} \mathrm{L}^{-1}$ phosphoric acid/sodium dihydrogen phosphate system at $\mathrm{pH} 1.55$ was chosen as separation buffer. As a conclusion, a fast and reliable method was developed for the determination of melittin in honeybee venom. The method was applied to an Anatolian bee venom sample

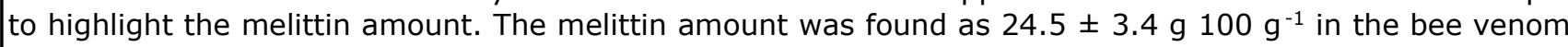
sample.
\end{abstract}

Keywords: Apitherapy, Apitoxin, Melittin, Capillary electrophoresis, Bee venom.

Submitted: June 08, 2021. Accepted: November 05, 2021.

Cite this: Akay M, Kalaycıoğlu Z, Kolaylı S, Erim FB. Comparative Determination of Melittin by Capillary Electrophoretic Methods. JOTCSA. 2021;8(4):1211-6.

DOI: https://doi.org/10.18596/jotcsa.949188.

*Corresponding author. E-mail: erim@itu.edu.tr.

\section{INTRODUCTION}

Honey bees (Apis mellifera L.) are one of the most important insects that associated with a number of anthropogenic activities (1). The most well-known examples are honey production, pollen, resins, wax, royal jelly, and bee venom which is also known as apitoxin (2). Extensive studies have been conducted on the substances produced by bees due to their numerous therapeutic applications (3-6).

Bee venom (BV) is one of the most important ones among the substances produced by bees (7). It is synthesized by the glands located in the abdomen of female worker bees (7). The medicinal application of bee venom, also known as bee venom therapy, has been used as an alternative medicine since ancient times (8). The application could be either indirectly by extracting bee venom with an electrical stimulus or directly via bee stings (7).

$\mathrm{BV}$ is a colorless liquid whose $\mathrm{pH}$ changes between 4.5-5.5. It consists of $88 \%$ water, while the remaining $12 \%$ contains peptides (such as melittin, adolapin, apamin, mast cell degranulating peptide), enzymes (such as phospholipase A2 and hyaluronidase), amino acids, and volatile compounds. The biological activities, including anticancer, anti-bacterial, anti-viral, anti-HIV, and antiinflammation of these components, have been reported $(9,10)$. Moreover, there are many studies on BV components that have potential treating 
effects on central nervous system diseases such as Alzheimer's disease (AD), Parkinson's disease (PD), and amyotrophic lateral sclerosis (ALS) (11).

One of the main components of bee venom is melittin. It is a toxic, water-soluble, and small peptide consisting of 26 amino acid residues (12).
The chemical structure of melittin was given in Figure 1. Various pharmacological, toxicological, and biological properties such as antifungal, antibacterial, and antiviral activities of melittin have been reported $(13,14)$. The inhibitory effect of melittin on the proliferation of different cancer cells and gastrointestinal cells (15).

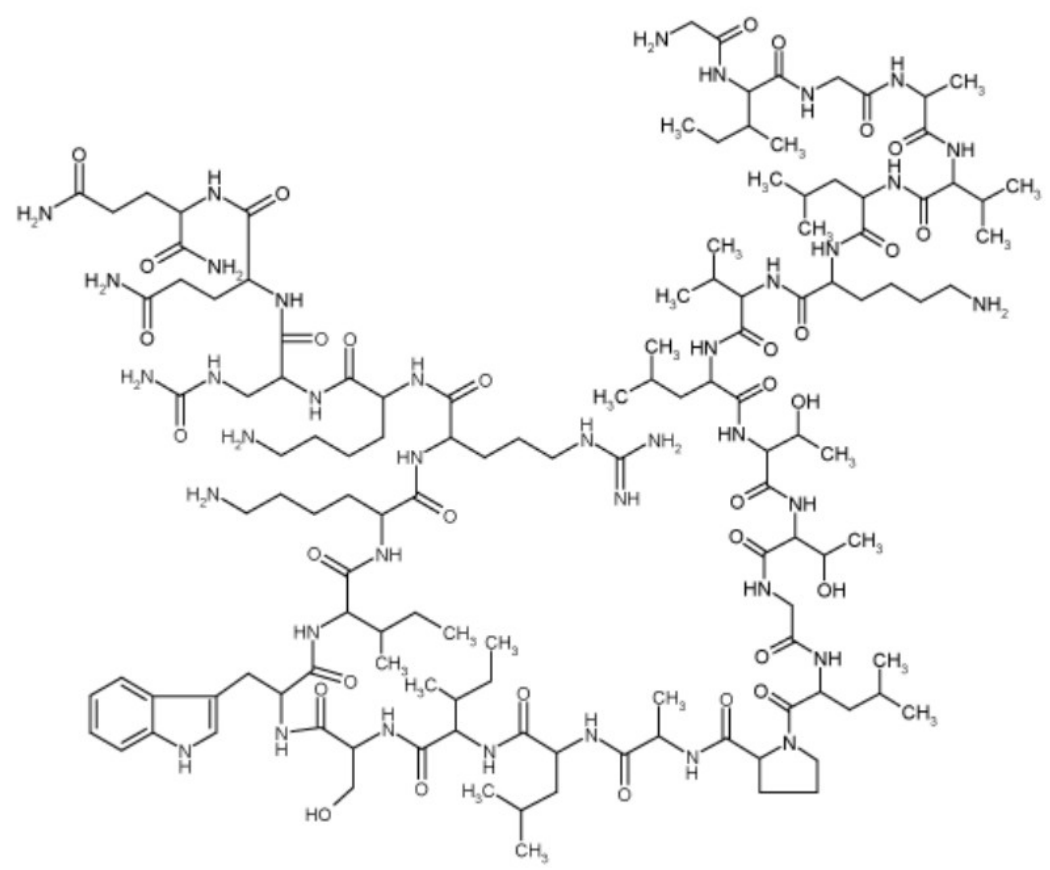

Figure 1: Structure of melittin.

During the last two decades, some investigations have been carried out in order to separate, identify, and quantify the major bee venom constituents. The majority of these studies are on liquid chromatography (16-21). A capillary electrophoresis technique was also applied to find the amounts of peptides, including melittin in bee venom samples (22). Among these studies, we could find only one study on Anatolian bee venom (21) by HPLC.

Many methods in order to characterize bee venom have been described. These either determine individual components or measure the biological effects of bee venom and its bioactive components.
It is known that the honeybee venom has a complex nature. Thus its content and the amount of the ingredients may depend on many factors such as the bee strain, the collection year and season, and the sample collection area. Only one CE method has been reported so far for the analysis of melittin (22). The highest melittin amount was determined in Polish bee venom samples with $70.1 \%$ in the literature (20). The samples from Iran (66.4\%) (16) and Romania (64.2\%) (18) followed the Polish bee venom (20). Whereas the lowest melittin amount found was in another Polish sample with $9.16 \%$ (19). The published results obtained from these studies were given in Table 1.

Table 1: The content of melittin in bee venom samples.

\begin{tabular}{lcll}
\hline Area of Sample Collection & Melittin $\left.\mathbf{( g ~ 1 0 0 ~} \mathbf{~ g}^{-\mathbf{1}}\right)$ & Method & Ref. \\
\hline Iran & $21.9-66.4$ & HPLC-PDA & $(16)$ \\
China & $33.9-46.2$ & UPLC-QqTOF-MS & $(17)$ \\
Romania & $27.7-64.2$ & HPLC-PDA & $(18)$ \\
Poland & $9.16-19.3$ & LC-DAD & $(19)$ \\
Poland & $61.1-70.1$ & HPLC-DAD & $(20)$ \\
Anatolia & $36.9-46.8$ & HPLC-UV & $(21)$ \\
Georgia and Poland & $25.4-60.3$ & CE-DAD & $(22)$ \\
\hline
\end{tabular}

Anatolia has a great beekeeping potential due to its very rich flora and suitable ecology. Determination of the active compounds in apicultural products is critical for diagnosing the quality of the products. In this study, a capillary electrophoretic technique has been developed for melittin. The developed 
technique has been applied for the determination of melittin in Anatolian honey bee venom.

\section{EXPERIMENTAL SECTION}

\section{Chemicals}

Standard melittin was from Sigma-Aldrich (Steinheim, Germany). Polyethyleneimine (PEI), orthophosphoric acid, acetic acid, hydrochloric acid, and sodium hydroxide were purchased from Merck (Darmstadt, Germany). All solutions were prepared with water purified by an Elga Purelab Option-7-15 model system (Elga, UK).

Dried bee venom sample were obtained from Düzce University, Beekeeping Research Development and Application Centre (DAGEM).

\section{Preparation of Standard Solution and Bee Venom Samples}

Standard solution of melittin was prepared at 1.0 $\mathrm{mmol} \mathrm{L}^{-1}$ level using distilled water and stored at deep freeze until the analysis. The calibration solutions were prepared by diluting the stock standard melittin solution (23). The calibration ranges were between $70-350 \mu \mathrm{g} \mathrm{mL}^{-1}$ for low $\mathrm{pH}$ buffer system and 35-350 $\mu \mathrm{g} \mathrm{mL}^{-1}$ for PEI-coated capillary column system.

One mg of crude bee venom sample was weighed. The extraction of melittin from bee venom was performed by deionized water. The mixture was vortexed for $5 \mathrm{~min}$ at $2500 \mathrm{rpm}$ and sonicated for $30 \mathrm{~min}$. The supernatant was filtered through a microfilter.

\section{Instrumentation and Conditions of Analysis}

A capillary electrophoresis/UV-DAD detector system (Agilent 1600, Waldbronn, Germany) was utilized for melittin analysis. The Agilent ChemStation software was used for the data processing. The separations were performed in a bare fused silica capillary and PEI coated fused silica capillary column. Both columns were $50 \mu \mathrm{m}$ i.d. (Polymicro Technology, Phoenix, AZ, USA). The length of the capillary column was $65 \mathrm{~cm}$ in total and the effective length was $57 \mathrm{~cm}$. In the bare fused silica column, the separation was performed at $25 \mathrm{kV}$. In the PEI-coated column, the separation was performed at $-25 \mathrm{kV}$. The temperature was set at 25 ${ }^{\circ} \mathrm{C}$, and injections were made at 50 mbar for $6 \mathrm{~s}$ in both approaches.

Before first use, the capillary was conditioned by rinsing with $1 \mathrm{~mol} \mathrm{~L}^{-1} \mathrm{NaOH}$ for 30 min followed by deionized water for $10 \mathrm{~min}$. At the beginning of each working day, the capillary was flushed with $1 \mathrm{~mol} \mathrm{~L}^{-1}$
$\mathrm{NaOH}$ for $15 \mathrm{~min}$, deionized water for $10 \mathrm{~min}$, and working buffer for $10 \mathrm{~min}$, respectively. Between runs, the capillary was flushed for 2 min with 1 mol $\mathrm{L}^{-1} \mathrm{NaOH}, 2$ min with deionized water, 5 min with buffer, respectively. For PEI coated column studies, the capillary was flushed by running buffer for 15 min at the beginning of every working day and running buffer for 2 min between runs.

In this study, we focused on two different approaches in order to prevent capillary wall's adsorption. The first approach is based on the low $\mathrm{pH}$ buffer system to suppress the negative wall charge significantly (24). The second approach is to coat the capillary inner wall with a suitable positively charged polymer such as PEI (25). Thus, the capillary inner wall is positively charged. In this case, injection is performed from the cathodic side.

\section{Dynamic Coating Process for Capillary Column}

The capillary coating process was performed as described in the literature (22). The fused silica capillary was flushed with $1 \mathrm{~mol} \mathrm{~L}^{-1} \mathrm{NaOH}$ solution for $30 \mathrm{~min}$ and then deionized water for $15 \mathrm{~min}$. Then the capillary was flushed with $10 \%(\mathrm{v} / \mathrm{v})$ PEI solution in water at $1000 \mathrm{mbar}$ for $10 \mathrm{~min}$. The solution of PEI was left in the capillary for one hour. After $1 \mathrm{~h}$, the PEI polymer solution was pressed out of the capillary with air at 1000 mbar. Finally, the capillary was rinsed with water for $15 \mathrm{~min}$ and running buffer for $15 \mathrm{~min}$.

\section{RESULTS AND DISCUSSION}

In the capillary electrophoretic separation of basic peptides such as melittin, the major difficulty is the possibility of capillary wall's adsorption. Efficiency of separation is decreased due to the capillary wall's adsorption. It occurs due to the electrostatic attraction which becomes between positively charged species and negatively charged silanol groups of the capillary wall.

Figure 2 was given for the comparison of the electropherograms of melittin which was performed at low $\mathrm{pH}$ (Figure 2A) and in PEI-coated silica column (Figure 2B). In the separation and identification of melittin which is performed at low $\mathrm{pH}, 100 \mathrm{mmol} \mathrm{L}^{-1}$ orthophosphoric acid/sodium dihydrogen phosphate buffer system at $\mathrm{pH} 1.55$ was chosen as the separation buffer (Fig. 2A). Whereas $50 \mathrm{mmol} \mathrm{L} \mathrm{L}^{-1}$ acetic acid/acetate buffer solution $(\mathrm{pH}$ 5.50) was performed in PEI-coated silica capillary column (Fig. 2B). The optimal concentrations of both buffer systems were found according to the peak symmetry and peak height of melittin. 


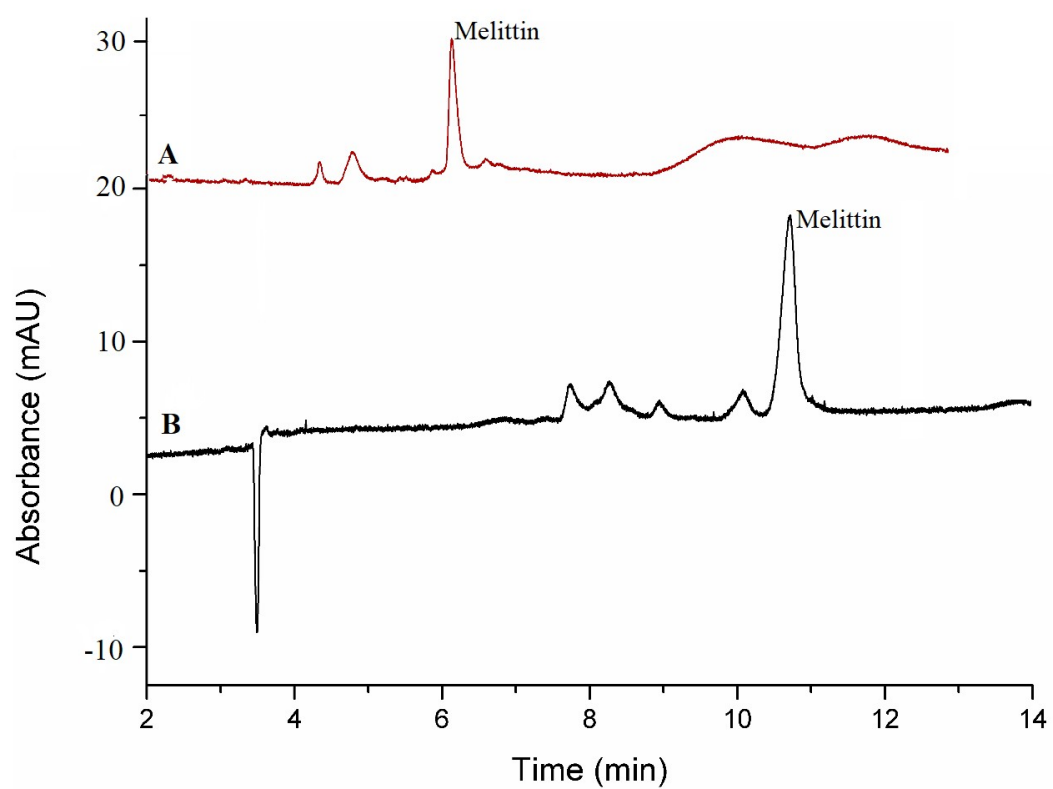

Figure 2: Electropherogram of $175 \mu \mathrm{g} \mathrm{mL}-1$ standard melittin solution. Conditions of analysis: (A): Bare fused silica column, Buffer: $100 \mathrm{mmol} \mathrm{L}^{-1}$ orthophosphoric acid at $\mathrm{pH} \mathrm{1.55;} \mathrm{Voltage:} 25 \mathrm{kV}$; (B): PEI-coated silica column, Buffer: $50 \mathrm{mmol} \mathrm{L}^{-1}$ acetic acid $\mathrm{pH} 5.50$; Voltage: $-25 \mathrm{kV}$ (Temperature: $25^{\circ} \mathrm{C}$; Injection: 50 mbar, $6 \mathrm{~s}$; Detection: UV-DAD detector, $\lambda: 200 \mathrm{~nm}$ )

Validation studies were performed for both two approaches, and the data was given in Table 2 . Calibration curves were constructed by plotting corrected peak areas versus analyte concentrations. The precision of the method was tested by intraand inter-day precisions. For the intra-day precision of the methods, standard melittin was injected five times in one day, and for the inter-day precision, it was injected 15 times in three days. The LOD and the LOQ values were calculated as three times and ten times of the average noise taken from three different baseline areas, respectively.

The RSD\% values of both methods are below the values accepted for CE analysis. The LOD value appears slightly lower in the PEI coated column than the uncoated column in the separation. However, considering the amount of melittin in bee venom, this difference does not become significant. Both methods seem suitable for analyzing melittin in bee venom. On the other hand, melittin's arrival time in low $\mathrm{pH}$ buffer in uncoated capillaries is significantly shorter than the time to arrival in capillaries coated with PEI (see Figure 2). Considering the time for coating procedure and the long arrival time of melittin peak for the separation in PEI coated capillary, it was decided that the uncoated capillarylow $\mathrm{pH}$ method is more advantageous in applying to actual bee venom samples.

Table 2: Method validation data for melittin.

\begin{tabular}{lll}
\hline Analytical Parameter & Low-pH buffer & PEI-coated capillary \\
\hline Intra-day precision (n=5) & & \\
$\quad$ Corrected peak area (RSD, \%) & 2.54 & 1.25 \\
$\quad$ Migration time (RSD, \%) & 3.12 & 2.13 \\
Inter-day precision (n=15) & & \\
$\quad$ Corrected peak area (RSD, \%) & 3.42 & 2.57 \\
$\quad$ Migration time (RSD, \%) & 4.84 & 3.16 \\
Linearity & & \\
$\quad$ Linear range ( $\mu$ mol L-1) & $70-350$ & $35-350$ \\
$\quad$ Regression equation & $\mathrm{y}=0.0004 \mathrm{x}-0.0158$ & $\mathrm{y}=0.0004 \mathrm{x}-0.0052$ \\
$\quad$ Correlation coefficient & 0.983 & 0.996 \\
LOD, $\boldsymbol{\mu m o l ~ \mathbf { L } ^ { - 1 }}$ & 19.3 & 10.0 \\
LOQ, $\boldsymbol{\mu m o l ~ L}^{-1}$ & 64.9 & 33.3 \\
\hline
\end{tabular}

Due to the advantage of a short analysis period, the method using low $\mathrm{pH}$ buffer was preferred for analyzing actual bee venom sample. The preparation of the sample solution was given above. The sample was analyzed in triplicate, and the standard deviation was calculated. One representative electropherogram of the bee venom sample is given in Figure 3. Melittin concentration of the bee venom sample was found as $24.5 \pm 3.4 \mathrm{~g}$ $100 \mathrm{~g}^{-1}$. 


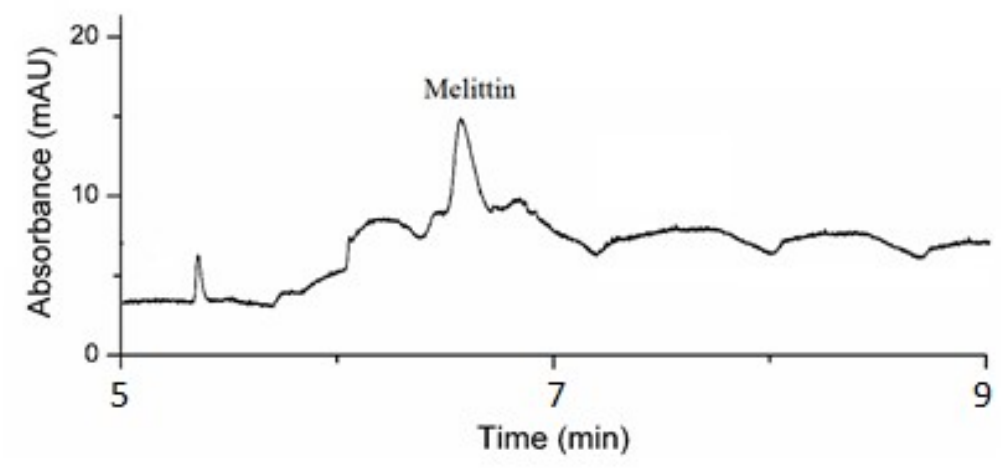

Figure 3: Bee venom sample extract. Analytic conditions: Bare fused silica column $(50 \mu \mathrm{m} \times 57 \mathrm{~cm})$, Buffer: $100 \mathrm{mM}$ orthophosphoric acid at pH 1.55; Voltage: $25 \mathrm{kV}$; Temperature: $25^{\circ} \mathrm{C}$; Injection: $50 \mathrm{mbar}$, $6 \mathrm{~s}$; Detection: UV-DAD detector, $\lambda: 200 \mathrm{~nm}$.

The amount of melittin detected in bee venom in this study is consistent with the values reported in different countries in the literature $(16,18-19,22)$. There is only one CE method reported for melittin analysis (22). However, in this literature study, the separation of melittin could be achieved in more than 20 minutes (22). Our method is much more rapid than the reported $\mathrm{CE}$ study for melittin. Moreover, melittin of an Anatolian honey bee venom was firstly highlighted using a CE method.

\section{CONCLUSION}

In this study, separation and quantification of melittin in an Anatolian honey bee venom sample was determined by capillary electrophoresis. In order to eliminate the capillary wall adsorption of positively charged melittin, two different methodologies were examined. Based on the rapid analysis, low-pH buffer system was selected for the analysis of the actual sample. By applying this methodology, melittin of Anatolian honey bee venom was highlighted. The method is presented as a fast and reliable method for screening and quantifying honeybee venom's melittin.

\section{CONFLICT OF INTEREST}

The authors have declared no conflict of interest.

\section{ACKNOWLEDGMENTS}

The authors would like to thank Assoc. Prof. Dr. Sibel Döşler for donating standard melittin. The Research Foundation of Istanbul Technical University was financially supported this study.

\section{REFERENCES}

1. Gupta RK, Stangaciu S. Apitherapy: Holistic Healing Through the Honeybee and Bee Products in Countries with Poor Healthcare System. In: Gupta RK, Reybroeck W, van Veen JW, Gupta A, editors. Beekeeping for Poverty Alleviation and Livelihood Security [Internet]. Dordrecht: Springer Netherlands; 2014 [cited 2021 Nov 6]. p. 413-46. ISBN: 978-94-017-9199-1. $\leq U R L>$.

2. Luo X, Dong Y, Gu C, Zhang X, Ma H. Processing Technologies for Bee Products: An Overview of Recent Developments and Perspectives. Front Nutr. 2021 Nov 3;8:727181. <DOI $>$.

3. Kalaycıoğlu Z, Kaygusuz H, Döker S, Kolaylı S, Erim FB. Characterization of Turkish honeybee pollens by principal component analysis based on their individual organic acids, sugars, minerals, and antioxidant activities. LWT. 2017 Oct;84:402-8. $\leq$ DOI $>$.

4. Kaygusuz H, Tezcan F, Erim FB, Yildiz O, Sahin $H$, Can $Z$, et al. Characterization of Anatolian honeys based on minerals, bioactive components and principal component analysis. LWT-Food Science and Technology. 2016 May;68:273-9. <DOI $>$.

5. Kaygusuz H. Analysis of a Rare Honey Sample From Tuzluca/Iğdır Region. Journal of the Institute of Science and Technology. 2020 Jun 1;1139-45. $\leq$ DOI $>$.

6. Sarikaya $A O$, Ulusoy $E$, Öztürk $N$, Tunçel $M$, Kolayli S. Antioxidant Activity And Phenolic Acid Constituents Of Chestnut (Castania Sativa Mill.) Honey And Propolis. Journal of Food Biochemistry. 2009 Aug;33(4):470-81. <DOI>.

7. Ali M. Studies on Bee Venom and Its Medical Uses. 2012;1:1-15. 
8. Bellik Y. Bee Venom: Its Potential Use in Alternative Medicine. AIA. 2015 May 20;13(1):3-16. $\leq$ DOI $>$.

9. Wehbe $R$, Frangieh J, Rima $M$, El Obeid $D$, Sabatier J-M, Fajloun Z. Bee Venom: Overview of Main Compounds and Bioactivities for Therapeutic Interests. Molecules. 2019 Aug 19;24(16):2997. $\leq$ DOI $>$.

10. Uzuner SÇ, Birinci E, Tetikoğlu S, Birinci C, Kolaylı S. Distinct Epigenetic Reprogramming, Mitochondrial Patterns, Cellular Morphology, and Cytotoxicity after Bee Venom Treatment. PRA. 2021 Aug; 16(3):377-92. $\leq \mathrm{DOI}>$.

11. Silva J, Monge-Fuentes V, Gomes F, Lopes K, Anjos L, Campos G, et al. Pharmacological Alternatives for the Treatment of Neurodegenerative Disorders: Wasp and Bee Venoms and Their Components as New Neuroactive Tools. Toxins. 2015 Aug 18;7(8):3179-209. <DOI>.

12. Kim W. Bee Venom and Its Sub-Components: Characterization, Pharmacology, and Therapeutics. Toxins. 2021 Mar 7;13(3):191. <DOI>.

13. Alia O, Laila M, Antonious A. Antimicrobial Effect of Melittin Isolated From Syrian Honeybee (Apis Mellifera) Venom and Its Wound Healing Potential. Int J Pharm Sci Rev Res. 2013;21:318-24.

14. Raghuraman H, Chattopadhyay A. Melittin: a Membrane-active Peptide with Diverse Functions. Bioscience Reports. 2007 Aug 6;27(4-5):189-223. $\leq$ DOI $>$.

15. Rady I, Siddiqui IA, Rady M, Mukhtar H. Melittin, a major peptide component of bee venom, and its conjugates in cancer therapy. Cancer Letters. 2017 Aug;402:16-31. <DOI>.

16. Haghi G, Hatami A, Mehran M. Qualitative and quantitative evaluation of melittin in honeybee venom and drug products containing honeybee venom. Journal of Apicultural Science. 2013 Dec $1 ; 57(2): 37-44$. $\leq \mathrm{DOI}>$.
17. Huang S, Wang J, Guo Z, Wang Y, Liu C. Quantitative Measurement of Melittin in Asian Honeybee Venom Using a New Method Including UPLC-QqTOF-MS. Toxins. 2020 Jul 4;12(7):437. $\leq \mathrm{DOI}>$.

18. Ionete $\mathrm{R}$, Dinca $\mathrm{O}$, Tamaian $\mathrm{R}$, Geana $\mathrm{E}$. Exploring Apis Mellifera Venom Compounds Using Highly Efficient Methods. Progress of Cryogenics and Isotopes Separation. 2013;16:89-100.

19. Kokot ZJ, Matysiak J. Simultaneous Determination of Major Constituents of Honeybee Venom by LC-DAD. Chroma. 2009 Jun;69(1112):1401-5. $\leq \mathrm{DOI}>$.

20. Rybak-Chmielewska H, Szczêsna T. HPLC Study of Chemical Composition of Honeybee (Apis Mellifera L.) Venom. J Apic Sci. 2004;48:103-9.

21. Samanci $T$, Kekeçoğlu M. Comparison of Commercial and Anatolian Bee Venom in Terms of Chemical Composition. Uludağ Arıcılık Dergisi. 2019 May 29;61-8. $\leq$ DOI $>$.

22. Kokot ZJ, Matysiak J, Urbaniak B, Dereziński P. New CZE-DAD method for honeybee venom analysis and standardization of the product. Anal Bioanal Chem. 2011 Mar;399(7):2487-94. <DOI>.

23. Barwick V, editor. Eurachem/CITAC Guide: Guide to Quality in Analytical Chemistry: An Aid to Accreditation [Internet]. Available from: www.eurachem.org. ISBN: 978-0-948926-32-7.

24. Chen F-TA, Evangelista RA. Protein analysis by capillary electrophoresis. In: Shintani H, Polonský J, editors. Handbook of Capillary Electrophoresis Applications [Internet]. Dordrecht: Springer Netherlands; 1997 [cited 2021 Nov 6]. p. 173-97. ISBN: 978-94-009-1561-9. $\leq U R L>$.

25. Erim FB, Cifuentes A, Poppe H, Kraak JC. Performance of a physically adsorbed highmolecular-mass polyethyleneimine layer as coating for the separation of basic proteins and peptides by capillary electrophoresis. Journal of Chromatography A. 1995 Aug;708(2):356-61. <DOI $>$. 